\title{
Efeito da massagem clássica estética em adiposidades localizadas: estudo piloto
}

\author{
Effects of classic aesthetic massage on localized adiposity: a pilot study
}

\author{
Pascale Mutti Tacani ${ }^{1}$, Aline Fernanda Perez Machado 2 , Daisy Aparecida do Amaral Souza ${ }^{2}$, Rogério Eduardo Tacani ${ }^{3}$
}

Estudo desenvolvido no Depto. de Fisioterapia da USCS Universidade Municipal de São Caetano do Sul, São Caetano, SP, Brasil

1 Fisioterapeuta; Profa. Ms. da USCS

2 Fisioterapeutas especialistas em Fisioterapia Dermato-Funcional

3 Fisioterapeuta; Prof. Ms. Coordenador do Programa de Pós-Graduação Lato Sensu em Fisioterapia Dermato-Funcional da Universidade Cidade de São Paulo, São Paulo, SP

ENDEREÇO PARA CORRESPONDENNCIA:

Pascale M. Tacani

R. Santo Antônio 50 09521-160 São Caetano do Sul SP e-mail: pascale.tacani@hotmail.com

\section{APRESENTAÇÃO}

abr. 2009

\section{ACEITO PARA PUBLICAÇÃO}

set. 2010
Resumo: Devido ao padrão de beleza imposto atualmente, tem aumentado a procura por tratamentos estéticos como a massagem clássica, porém sua suposta ação lipolítica ainda é uma questão controversa na literatura. O objetivo deste estudo foi verificar o efeito da massagem clássica estética nas adiposidades localizadas, por meio de perimetria do abdome, quadril e coxas e pela estimativa da espessura da tela subcutânea da parede abdominal (ETS) por ultrassonografia. Oito voluntárias (idade 33,9 98,9 anos, peso $65,1 \pm 8,4 \mathrm{~kg}$ ) foram avaliadas quanto a MC, IMC e ETS 30 dias antes, logo antes do início da intervenção e após esta. Foram efetuadas 12 sessões de massagem clássica estética em coxas, glúteos e abdome por 30 minutos, três vezes por semana. Foi encontrada redução significativa apenas da perimetria na região do quadril $(p=0,012)$, mas não da ETS $(p=0,301)$. A massagem clássica estética contribuiu apenas para a redução da perimetria do quadril, e não modificou outras medidas nem a espessura da tela subcutânea da região abdominal.

Descritores: Adiposidade; Massagem; Gordura subcutãnea; Ultrassonografia

Abstract: Due to current beauty standards, the search for aesthetic treatments, including classical massage, has increased; however, its presumed lipolytic action is still controversial in literature. The purpose of this study was to assess the effect of classical massage on localized adiposity, by means of abdomen, hip and thigh perimeter measuring, nd by estimating thickness of abdominal wall fat by ultrasonography. Eight volunteers $(33.9 \pm 8.9$ years old, $65.1 \pm 8.4 \mathrm{~kg})$ were assessed as to weight, body mass index, body perimeter measures and by abdomen ultrasonography at three moments: control (30 days before treatment), just before, and after treatment. The latter consisted of 12 thrice-weekly, 30-minute massage sessions on thighs, buttocks, and abdomen. Results showed a significant reduction at hip perimeter $(p=0.012)$, but none of subcutaneous fat tissue thickness $(p=0.301)$. Classical aesthetic massage hence did not modify abdominal wall fat, but did reduce hip perimeter.

Key words: Adiposity; Massage; Subcutaneous fat; Ultrasonography 


\section{INTRODUÇÃO}

Devido ao padrão de beleza imposto atualmente, somado ao crescimento do número de pessoas obesas e com sobrepeso no Brasil1, observa-se insatisfação com a imagem corporal e maior preocupação e desconforto com o corpo ${ }^{2}$, aumentando a procura por tratamentos estéticos ${ }^{3}$. As mulheres (84,3\%) são as que mais procuram tais tratamentos, provavelmente porque as alterações hormonais e ponderais podem provocar aumento de peso, volume e alterações do contorno corporal $(78,2 \%$ de pacientes obesas), conforme apontaram Tacani et al. ${ }^{4}$ no estudo do perfil de pacientes atendidos em fisioterapia dermato-funcional.

Dessa forma, cresce a procura por massagens tidas como 'redutoras' ou 'modeladoras' e, por isso, observa-se sua grande oferta em serviços e clínicas de estética, muitas aplicadas por profissionais não-qualificados, como mostrou o censo de 2008 do Crefito-3, notificando 1.300 estabelecimentos no Estado de São Paulo que ofereciam esses métodos sem profissionais habilitados 5 .

Quando executada adequadamente, a massagem clássica estética pode auxiliar na redução de medidas e edemas6, estimular a circulação sangüínea, o metabolismo e as respostas neuromusculares, harmonizar os contornos corporais e minimizar a ansiedade e a depressão, contribuindo para o aumento da auto-estima e da qualidade de vida 7 .

Entretanto, a ação da massagem clássica no tecido adiposo ainda é um tema extremamente controverso, pois alguns autores acreditam não haver qualquer efeito lipolítico primário sobre o tecido adiposo, enquanto outros relatam um efeito lipolítico secundário quando associado a dieta e atividade física; outros ainda referem um efeito lipolítico primário $^{7}$. Poucos estudos avaliam de maneira objetiva e quantitativa os efeitos das técnicas manuais na adiposidade, como mostram Tunay et al. 8 , ao compararem três recursos de massagem - dermotonia, drenagem linfática manual associada a compressão elástica e massagem do tecido conjuntivo - no tratamento da adiposidade: observaram redução significante da massa e das medidas corporais com os três recursos, mas relatam a necessidade de mais estudos para confirmar os efeitos da massagem no tecido adiposo e na circulação sangüínea e linfática.

Para quantificar a eficácia de tratamentos emagrecedores, diversos métodos se propõem a mensurar a distribuição da gordura corporal, por impedância bioelétrica, pesagem subaquática, adipometria, ultrassonografia (USG), antropometria (massa corporal, estatura, circunferências, relação cintura-quadril e o cálculo do índice de massa corporal - IMC), dentre outros $^{9-12}$; mas, na prática clínica, nem todos estão disponíveis, por exigirem acesso a métodos laboratoriais ou preparo profissional especializado.

O objetivo desta pesquisa foi verificar os efeitos da massagem clássica estética nas adiposidades localizadas, por meio de perimetria do abdome, quadril e coxas e por estimativa da espessura da tela subcutânea (ETS), por ultrassonografia.

\section{METODOLOGIA}

Este estudo clínico foi iniciado após aprovação do Comitê de Ética em Pesquisa da Universidade Cidade de São Paulo e o consentimento livre e esclarecido das voluntárias.

Foram selecionadas dez voluntárias saudáveis, na faixa de 20 a 45 anos, com IMC entre 18,5 e 34,9 kg/m², biotipo ginóide, não-praticantes de atividade física, sem restrição alimentar ou dieta hipocalórica, sem uso de medicação anticoncepcional ou esteróide, dentre as universitárias e funcionárias da Universidade Municipal de São Caetano do Sul, SP. Foram excluídas voluntárias gestantes e/ou que apresentassem doenças metabólicas, hormonais e contra-indicações para a aplicação da massagem clássica.

As voluntárias foram submetidas a uma avaliação inicial quatro semanas antes de se começar a intervenção e orientadas a manter a mesma rotina de atividades diárias - no que foi considerado período controle. Findo esse período, foi feita uma 2a avaliação e procedeu-se ao tratamento durante quatro semanas, após o quê foram submetidas à $3 \underline{a}$ avaliação. Nos três momentos procedeu-se à avaliação fisioterapêutica e à USG na região abdominal. A massagem clássica estética foi aplicada três vezes por semana durante 30 minutos, sendo 6 minutos na região do abdome, 5 minutos em cada coxa ântero-medial e 7 minutos em cada coxa póstero-lateral e glúteos.

A avaliação fisioterapêutica foi feita sempre pelo mesmo avaliador, composta por anamnese e antropometria, aferindo-se MC (kg) e estatura (m) para obtenção do IMC $\left(\mathrm{kg} / \mathrm{m}^{2}\right)$, e perimetria $(\mathrm{cm})$. A adipometria não foi utilizada neste estudo por exigir treinamento e habilidade de um avaliador experiente. Para a avaliação antropométrica, as voluntárias deveriam ficar em bipedestação, com $30 \mathrm{~cm}$ de distância entre os pés, trajando roupas de banho com duas peças. Foi medido o perímetro nas regiões do abdome, quadril e membros inferiores (MMII). A padronização no abdome foi feita a partir da cicatriz umbilical, ápice inferior como marco zero, medindo-se 5 e 10 cm para cima, em direção ao esterno e $5 \mathrm{~cm}$ para baixo, em direção ao púbis. A perimetria de quadril foi estabelecida $10 \mathrm{~cm}$ abaixo do ápice inferior da cicatriz umbilical e nos MMII, a linha poplítea foi considerada como marco zero, medindo-se 5, 10, 15 e $20 \mathrm{~cm}$ em direção aos glúteos, à direita e, depois à esquerda. O exame de USG foi realiza por médico especialista em USG, padronizando a análise da região abdominal infra-umbilical direita, $2 \mathrm{~cm}$ abaixo da cicatriz umbilical e $2 \mathrm{~cm}$ à direita da linha alba, por ser a área de maior predomínio de receptores -adrenérgicos responsáveis pela ativação da lipólise 13 . Tanto a avaliação fisioterapêutica como a USG foram realizados por profissionais sem envolvimento com a pesquisa.

A massagem foi aplicada sempre pelo mesmo fisioterapeuta, com a voluntária em decúbito dorsal na maca, aplicando-se a técnica no abdome por 10 minutos e na região anterior das coxas e, em decúbito ventral, na região posterior das coxas e glúteos, ambos por 5 minutos em cada lado. Utilizou-se um creme para massagem e hidratação da pele (Peelline). As manobras da massagem clássica estética seguiram sentido centrípeto, ritmo constante, freqüência aproximada de 1 movimento a cada 5 segundos, intensidade e pressão moderadas, suficiente para atingir a camada muscular superficial, respeitando-se o limiar de dor das voluntárias e na seguinte seqüência: deslizamento superficial, deslizamento profundo, amassamento, rolamento de pele, alternância de polegares, pinçamentos alternados, tapotagem 
(apenas na região glútea) e percussão palmar (tapping). O deslizamento superficial foi executado com a palma das mãos e dos dedos de forma rítmica e suave. $\mathrm{O}$ deslizamento profundo, com a palma das mãos e dos dedos de forma mais intensa e profunda. $\mathrm{O}$ amassamento consistiu de compressões alternadas realizadas com o polegar e região tenar contra o indicador e dedo médio da mão oposta, em forma de pinçamento em 'S' dos tecidos. O rolamento de pele foi feito transportando uma prega de pele entre o polegar, indicador e dedo médio, ao longo de toda região a ser tratada. Com alternância dos polegares, foram efetuados deslizamentos pequenos e profundos da face ventral da falange distal dos polegares. Os pinçamentos alternados foram executados com pequenos movimentos de pinça, utilizando todos os dedos, que percutiam alternadamente os tecidos. A tapotagem consistiu de movimentos rítmicos realizados com as duas mãos em forma de concha e o tapping foi aplicado com a palma das mãos de forma rítmica, alternada e no sentido das fibras musculares (Figuras 1 e 2).

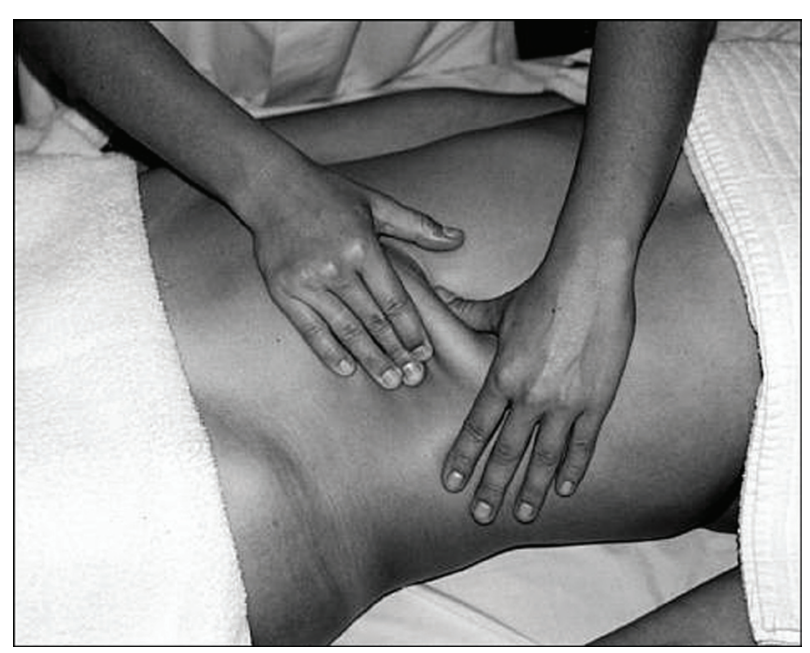

Figura 1 Amassamento na região abdominal

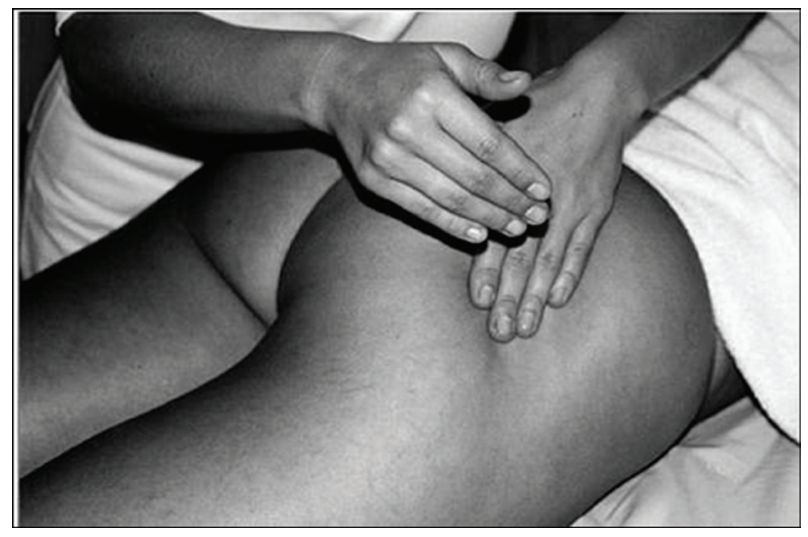

Figura 2 Tapping aplicado na região glútea
Para comparar os valores dos períodos controle e intervenção, foi utilizado o teste t de Student pareado; para as três avaliações foi aplicada a análise de variância Anova. Secundariamente, foi verificada correlação (r de Pearson) entre o perímetro abdominal e a espessura da camada de gordura subcutânea, considerando-se a correlação ausente quando $r<0,2$, ruim quando $0,20 \leq r<0,40$, regular se $0,40 \leq r<0,60$, boa quando $0,60 \leq r<0,80$ e ótima se $r \geq 0,80$; o nível de significância foi fixado em $5 \%(=0,05)$.

\section{RESULTADOS}

Dez voluntárias iniciaram sua participação no estudo, porém apenas oito o finalizaram, sendo uma excluída por não completar o tratamento e a outra pela constatação de hérnia abdominal após o primeiro exame de USG.

A idade variou de 21 a 41 anos, com

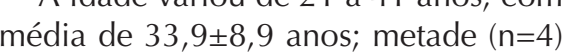
das voluntárias apresentaram IMC normal, três tinham sobrepeso e uma, obesidade grau I. Quanto à espessura da tela subcutânea, obtiveram-se os valores médios de 24,6 mm na 1ạ avaliação e $21 \mathrm{~mm}$ na última, sem diferença significante. Massa corporal, IMC e ETS não variaram significativamente ao longo das três avaliações, como mostra a Tabela 1.

Quanto à perimetria, só foi verificada diferença significante após a intervenção na circunferência do quadril $(p=0,012)$, como apontado na Tabela 2.

Como esperado, foi encontrada boa correlação significativa entre a circunferência do abdome inferior e a ETS da parede abdominal $(r=0,70 ; p<0,001)$.
DISCUSSÃO

O presente estudo investigou o efeito da massagem clássica estética nas adiposidades localizadas de oito voluntárias com IMC entre 20,6 kg/m² e 31,3 kg/ $\mathrm{m}^{2}$. Após a massagem clássica estética, observou-se manutenção da MC e do IMC, com redução apenas da perimetria do quadril $(p=0,012)$, mas não da espessura da tela subcutânea da região abdominal $(p=0,301)$.

Metade $(n=4)$ das voluntárias foram classificadas pelo IMC como de peso normal, mas mesmo assim apresentavam adiposidades localizadas e se queixavam desse aspecto inestético, tal como outras três que tinham sobrepeso e uma com obesidade grau I. Mesmo mulheres com IMC considerado normal podem apresentar porcentagem de gordura corporal acima do preconizado, pois esse índice não avalia os compartimentos de massa magra e gorda, não acusando assim adiposidades localizadas 14

O método de avaliação empregado é amplamente utilizado tanto na prática clínica como em pesquisa, por ser considerado método prático, de baixo custo e por avaliar a massa corporal de forma não-invasiva11,15-17. Tunay et al. 8 avaliaram o efeito de três tipos de tratamento fisioterapêutico (drenagem linfática manual associada a contenção elástica, dermotonia e massagem do tecido conjuntivo) sobre a espessura do tecido subcutâneo em 60 mulheres com fibroedema gelóide, também utilizando antropometria, tendo obtido redução significante de medidas; porém, pela impedância bioelétrica não foi observada alteração da composição corporal.

Neste estudo, a perimetria revelou-se uma ferramenta acessível, prática, de baixo custo, de resultado imediato e capaz de detectar alterações na população estudada, podendo ser utilizada de forma segura quando não for possível utilizar os métodos laboratoriais, tanto por serem mais caros como demandarem mais tempo entre a realização e o resultado. Randominski et al. 10 compararam a USG e a tomografia computadorizada (TC) na determinação da gordura visceral e concluíram que a USG foi mais prática, barata e segura, além de evitar o aspecto negativo das radiações da TC, podendo ser repetida conforme o necessário. 
Tabela 1 Idade, massa corporal (MC), índice de massa corporal (IMC) e espessura da tela subcutânea da parede abdominal (ETS) (média \pm desvio padrão) das voluntárias $(n=8)$ nas três avaliações $(A v)$, e valor de $p$ da comparação entre a $1 \mathrm{a}$ e $2^{\mathrm{a}}$ avaliações e entre a $2^{\mathrm{a}}$ e $3^{\mathrm{a}}$ avaliações

\begin{tabular}{|c|c|c|c|c|c|c|c|c|c|}
\hline \multirow{2}{*}{ Idade } & \multicolumn{3}{|c|}{$\mathrm{MC}(\mathrm{kg})$} & \multicolumn{3}{|c|}{$\mathrm{IMC}\left(\mathrm{kg} / \mathrm{m}^{2}\right)$} & \multicolumn{3}{|c|}{ ETS (mm) } \\
\hline & 1a Av & $2 \underline{a} \mathrm{Av}$ & $3 \underline{a} A v$ & $1 \underline{a} A v$ & 2a $A v$ & $3 \underline{a} \mathrm{Av}$ & $1 \underline{a} A v$ & 2a $\mathrm{a}$ Av & $3 \underline{a} A v$ \\
\hline $33,9 \pm 8,9$ & $65,1 \pm 8,37$ & $64,5 \pm 7,86$ & $64,0 \pm 7,84$ & $25,5 \pm 3,17$ & $25,5 \pm 3,41$ & $25,4 \pm 3,60$ & $24,6 \pm 9,46$ & $24,9 \pm 10,61$ & $21,0 \pm 9,98$ \\
\hline$p$ & 0,909 & & 0,815 & 0,685 & & 0,476 & 0,694 & & 0,301 \\
\hline
\end{tabular}

Tabela 2 Medidas dos perímetros $(\mathrm{cm})$ do abdome, quadril e coxas (média \pm desvio padrão) das voluntárias ( $\mathrm{n}=8$ ) nas três avaliações (Av), e valor de $p$ da comparação entre a 1a e $2 \underline{a}$ avaliações e entre a $2 \underline{a}$ e $3 \underline{a}$ avaliações

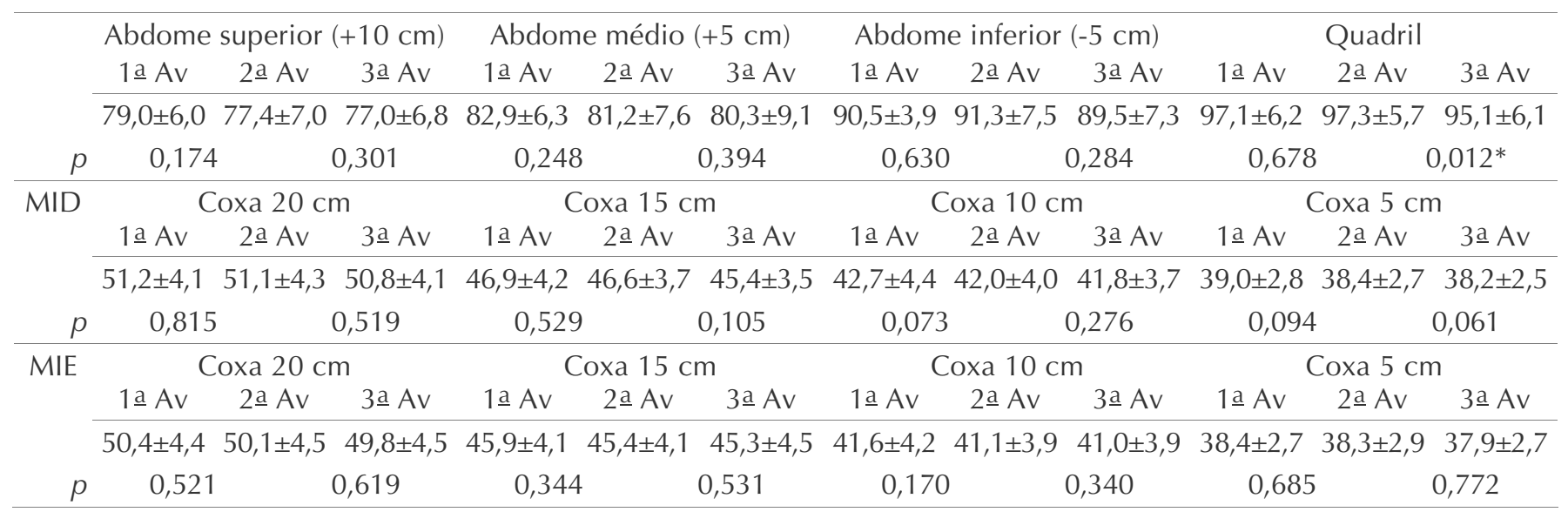

Da mesma maneira, Leite et al. ${ }^{9}$ compararam a USG e a circunferência abdominal como meios de determinar a gordura intra-abdominal e o risco de doença cardiovascular, concluindo que a USG é um método prático e melhor que a circunferência abdominal nessa situação. Neste estudo, também se observou praticidade, segurança e eficácia na determinação da espessura da tela subcutânea de forma não-invasiva pela USG, demonstrando ser esta uma opção válida de mensuração na prática clínica - porém não de baixo custo em relação à antropometria, pois essa foi uma das limitações para a aplicação da USG em diversas áreas corporais das voluntárias.

As mulheres são as que mais procuram tratamentos estéticos, provavelmente porque as alterações hormonais e ponderais podem provocar aumento de peso, volume e alterações do contorno corporal ${ }^{4}$. Por isso, neste estudo foi determinado o período de um mês de controle, sem intervenção, para verificar se haveria alterações na composição corporal; e, como não foram observadas diferenças significantes entre a 1a e a $2 \underline{a}$ avaliações, os achados da última avaliação certamente refletem os efeitos do tratamento proposto.
A hereditariedade e o biotipo tornam as mulheres propensas ao depósito de células adiposas nas regiões fêmuro-glúteas, porque os adipócitos dessas regiões respondem melhor ao estrógeno, sendo menos sensíveis aos hormônios lipolíticos, além de deterem mais receptores $\alpha$-adrenérgicos, responsáveis pela inibição da lipólise. Esses fatores induzem ao aumento do tamanho das células e, como conseqüência, aumentam a espessura da tela subcutânea, favorecendo a infiltração edematosa 13 .

Diferentemente, o comportamento do tecido adiposo da região abdominal é muito mais variável, pois os adipócitos respondem melhor aos hormônios lipolíticos, além de apresentarem predomínio de receptores $\beta$-adrenérgicos, responsáveis pela ativação da lipólise ${ }^{13}$. Assim, ao se observar o comportamento lipolítico dessa região, esperava-se que as voluntárias submetidas à massagem apresentassem redução de medidas mais facilmente no abdome; porém, no presente estudo observou-se redução significante apenas da perimetria do quadril, provavelmente pelo estímulo do metabolismo local 6 que teria gerado uma situação genérica de estresse, au- mentando a ação das catecolaminas 18 , além de aumentar a absorção de líquidos ou edemas intersticiais 8 . Na região abdominal, a massagem não estimulou a redução da espessura da tela subcutânea; na população estudada, provavelmente o tempo de aplicação na região do abdome não tenha sido suficiente para promover efeitos lipolíticos, pois foi menor (6 minutos) quando comparado ao do quadril (14 minutos, sendo 7 de cada lado). Além disso, a somatória de manobras antiaderentes e estimulantes na técnica de massagem clássica pode ter promovido estimulação do sistema nervoso autônomo parassimpático, tendo como efeito o relaxamento e não a situação de estresse promovida por manobras estimulantes que levam à maior reação simpática 18-20, principalmente porque na região do quadril foi acrescentada a manobra de tapotagem, contra-indicada na região abdominal (devido à sua fragilidade e presença das vísceras) 18,19 .

Estudos semelhantes apresentam resultados contraditórios. Pedini e Zaietta20 verificaram a ação de faixas de vibromassagem sobre o tecido adiposo de 12 voluntários submetidos a 14 sessões diárias de 20 minutos, observando, em 10 dos 12 
casos, aumento significativo do glicerol plasmático e da concentração de ácidos graxos livres, enquanto Benelli et al.21 aplicaram 40 minutos de massagem mecânica no abdome e coxas de 10 pacientes obesas (com IMC médio de 35,5 kg/m²) e não observaram alterações significativas de níveis plasmáticos que indicassem a ocorrência de lipólise - mas relatam melhora dos contornos corporais e do aspecto do tecido adiposo subcutâneo.

Quanto ao efeito lipolítico primário da massagem, De Domenico e Wood 18 alegam que são inúteis as tentativas de redução de gordura localizada; Holey e $\operatorname{Cook}^{22}$ concluem que ainda não há evidência plausível quanto aos efeitos lipolíticos da massagem. Rosenthal (apud Wood \& Becker23) não constatou qualquer alteração histológica no tecido adiposo após realizar manobras vigorosas de massagem na região abdominal de animais; e, para Fricker et al.24, a massagem faz "emagrecer o massagista".

Em contrapartida, a mobilização mecânica de pré-adipócitos in vitro diminuiu a diferenciação em adipócitos no estudo de Tanabe et al. 25 , fornecendo uma base molecular para a aplicação local desses estímulos na prevenção das adiposidades localizadas. Cassar19 relata que a manobra de amassamento na massagem clássica tende a produzir um efeito de emulsificação lipídica melhorando a absorção lipídica e seu metabolismo. Tunay et al. 8 compararam o efeito de três recursos - massagem mecânica (dermotonia, 15 sessões, 3 vezes por semana), drenagem linfática manual (20 sessões, 4 vezes por semana) e massagem do tecido conjuntivo (20 sessões, 4 vezes por semana) - em 60 mulheres com idade média de 40 a 43 anos e IMC de 24 a $25 \mathrm{~kg} / \mathrm{m}^{2}$, observando diminuição significante de $0,5 \mathrm{~cm}$ na perimetria de coxa e na espessura do tecido adiposo em todos os grupos. Referem que todas as técnicas de tratamento foram efetivas na diminuição da adiposidade e do fibroedema e, comparativamente a massagem mecânica foi mais eficaz na mobilização de gordura e reabsorção de líquido intersticial no tecido celular subcutâneo. Para Tacani e Cervera26, a massagem pode auxiliar nos processos de emagrecimento por melhorar a aparência da pele e seus contornos, estimular as funções viscerais e diminuir a ansiedade e o estresse. Tais aspectos psicossomáticos se relacionam com a insatisfação e distorção da imagem corporal percebida tanto por indivíduos eutróficos como obesos 2,27 e a massagem pode contribuir para a melhora da imagem corporal e para a redução da gordura subcutânea, como demonstrou Kim28, ao aplicar semanalmente, durante 6 semanas, massagem associada à aromaterapia em 35 mulheres, no período pós-menopausa, observando redução da circunferência da cintura, da gordura subcutânea abdominal e melhora da imagem corporal.

Apesar de resultados promissores, a literatura requer mais esclarecimento a respeito dos mecanismos de ação dos recursos manuais na lipólise e a conseqüente redução da massa corporal. Sugere-se a realização de novos estudos com delineamento semelhante a este, utilizando o exame de USG e a perimetria nos mesmos segmentos corporais, porém com uma amostra maior, contemplando diferentes graus de IMC.

\section{CONCLUSÃO}

A massagem clássica estética não produziu redução de massa corporal, IMC, nem da espessura da tela subcutânea da região abdominal, mas contribuiu para a redução do perímetro do quadril.

\section{REFERENCIAS}

1 Paula RM, Simões NP, Picheth G. Efeitos da eletrolipoforese nas concentrações séricas do glicerol e do perfil lipídico. Fisioter Bras. 2007;3(Supl esp):5-9.

2 Kakeshita IS, Almeida SS. Relação entre índice de massa corporal e a percepção da auto-imagem em universitários. Rev Saude Publica. 2006;40(3):497-504.

3 Almeida ACN, Carneiro CH, Araújo DR, Santos FP, Vieira Neto JM, Marino MAP, et al. Corpo, estética e obesidade: reflexões baseadas no paradigma da indústria cultural. Estudos [UCG, Goiânia]. 2006;33(5):789-812.

4 Tacani PM, Machado AFP, Tacani RE. Perfil clínico dos pacientes atendidos em fisioterapia dermatofuncional na clínica da USCS. Rev Bras Cienc Saude. 2009;7(21):36-44.

5 Peres LP. Drenagem linfática: deve ser oferecida apenas por profissionais habilitados. Revista Crefito-3. 2008;5(1):32-3.

6 Neves SR, Oliveira D. Eficácia da associação de técnicas manuais e eletrotermoterapia na redução de medidas do abdome. Rev Biol Saude Unisep. 2008;1(1):67-71.
7 Tacani RE, Tacani PM. Drenagem linfática manual terapêutica ou estética: existe diferença? Rev Bras Cienc Saude. 2008;17:71-7.

8 Tunay VB, Akbayrak T, Bakar Y, Kayihan H, Ergun N. Effects of mechanical massage, manual lymphatic drainage and connective tissue manipulation techniques on fat mass in women with cellulite. J Eur Acad Dermatol Venereol. 2010;24(2):138-42.

9 Leite CC, Matsuda D, Wajchenberg BL, Cerri GG, Halpern A. Correlação da medida de espessura intraabdominal medida pela ultrassonografia com os fatores de risco cardiovascular. Arq Bras Endocrinol Metab. 2000;44(1):49-56.

10 Radominski RB, Vezozzo DP, Cerri GG, Halpern A. O uso da ultrassonografia na avaliação da distribuição da gordura abdominal. Arq Bras Endocrinol Metab. 2000;44(1):5-12.

11 Rodrigues Barbosa A, Santarém JM, Jacob Filho W, Meirelles ES, Marucci MFN. Comparação da gordura corporal de mulheres idosas segundo antropometria, bioimpedância e DEXA. Arch Latinoam Nutr. 2001;51(1):49-56. 


\section{Referências (cont.)}

12 Cabrera MAS, Wajngarten M, Gebara OCE, Diament J. Relação do índice de massa corporal, da relação cintura-quadril e da circunferência abdominal com a mortalidade em mulheres idosas: seguimento de 5 anos. Cad Saude Publica. 2005;21(3):767-75.

13 Ciporkin H, Paschoal L. Avaliação terapêutica e fisiopatogênica da lipodistrofia ginóide. São Paulo: Santos; 1992.

14 Machado AFP, Tacani RE, Schwartz J, Liébano RE, Ramos JLA, Frare T. Incidência de fibroedema gelóide (celulite) em mulheres caucasianas jovens. Arq Bras Cienc Saude. 2009;7(21):36-44.

15 Costa RS, Sichieri R. Relação entre sobrepeso, adiposidade e distribuição de gordura com a pressão arterial de adolescentes no município do Rio de Janeiro. Rev Bras Epidemiol. 1998;1(3):268-79.

16 Abrantes M, Larmounier JA, Colosimo E. Prevalência de sobrepeso e obesidade em crianças e adolescentes das regiões Sudeste e Nordeste. J Pediatr. 2002;78(4):335-40.

17 Glaner MF. Índice de massa corporal como indicativo da gordura corporal comparado às dobras cutâneas. Rev Bras Med Esporte. 2005;11(4):243-6.

18 De Domenico G, Wood EC. Técnicas de massagem de Beard. 4a ed. São Paulo: Manole; 1998.

19 Cassar MP. Manual de massagem terapêutica. São Paulo: Manole; 2001.

20 Pedini G, Zaietta P. Su alcuni aspetti della attivazione della lipolisi tessutale da parte di fattori meccanici. Minerva Med. 1975;66(7):318-23.

21 Benelli L, Berta JL, Cannistra C. Amram P, Benhamou G. Endermologie: humoral repercussions and estrogen interaction. Aesth Plast Surg. 1999;23(5):312-5.
22 Holey EA, Cook EM. Therapeutic effects. In: Holey EA, Cook EM. Therapeutic massage. London: WB Saunders; 1997. p.21-38.

23 Wood EC, Becker PD. Massagem de Beard. 3a ed. São Paulo: Manole; 1990.

24 Fricker J, Melchior JC, Duchemin M, Thoumie P, Apfelbaum M. Masso-kinésitherapie et reéducation dans I'obesité. In: Encyclopédie médicale et chirurgicale: Kinésitherapie-Médicine physique-Réadaptation. Paris: Elsevier; 1988. 26-580-A-10, p.1-8.

25 Tanabe Y, Koga M, Saito M, Matsunaga Y, Nakayama K. Inhibition of adipocyte differentiation by mechanical stretching through ERK-mediated downregulation of PPARg2. J Cell Sci. 2004;117(16):3605-14.

26 Tacani RE, Cervera L. Técnicas manuais. In: De Maio M. Tratado de medicina estética. São Paulo: Roca; 2004. p.1881-915.

27 Araújo CL, Dumith SC, Menezes AMB, Hallal PC. Peso medido, peso percebido e fatores associados em adolescentes. Rev Panam Salud Publica. 2010;27(5):360-7.

28 Kim HJ. Effect of aromatherapy massage on abdominal fat and body image in post-menopausal women. Taehan Kanho Hakhoe Chi. 2007;37(4):603-12.

\section{AGRADECIMENTO}

Os autores agradecem a contribuição logística do Sr. Valério Antonio do Amaral para a realização desta pesquisa. 